\title{
The Relationship Between Life Satisfaction and Decision-Making Strategies for Sports Sciences Students of Kocaeli University, Turkey
}

\section{Tolga Kaan Bahadir}

Kocaeli University, Kocaeli, Turkey

Study Area: Kocaeli, Turkey

Coordinates: $40.7661^{\circ} \mathrm{N} ; 29.9394^{\circ} \mathrm{E}$

Key words: Physical Education, Covid-19, Pandemic Year

\section{Abstract}

The research group consists of randomly selected 213 students, 150 boys and 63 girls studying at the Faculty of Sports Sciences of Kocaeli University in Kocaeli province. Qualitative data collection method was used in this study. As a data collection tool, the Personal Information, decision strategies scale, life satisfaction scale were used in the research. As a result of the study, it was observed that there were significant differences between participants ' gender, which class they were students in, and their decisionmaking strategies. In addition, it was found that there were significant differences between family support and life satisfaction levels of participants. Looking at the age variable of participants, no significant correlation coefficient was found between decision-making strategies and life satisfaction levels. Conclusively, there was a positive correlation between participants' life satisfaction levels and decision-making strategies.

\section{Introduction:}

Today, the sport has advanced very quickly with technology and has come to very different points. One of the most important reasons for this is the scientific research conducted by sports institutes, sports academies, and sports universities around the world. In Turkey, we can include faculties of Sports Sciences and colleges of physical education and sports. Especially in our country, it is very possible to say that people have been psychologically very worn out recently, and accordingly, students studying at the university have also been affected by this wear (especially the Covid-19 pandemic process). For this reason, we can say that determining how the relationship between life satisfaction and decision-making strategies of students studying in sports science faculties of universities are going to make a signif icant contribution to the education sector, and then to the quality of life of students.

One of the most important issues in people's lives is being happy. Material conditions, environmental conditions, disasters, etc. many issues are many factors that affect people's enjoyment of life. In the same way, people make decisions about their lives to be happy again and have better opportunities. For this reason, especially young people who decide to study at university make their most critical decisions again in this process and try to continue in this direction throughout their lives.
Satisfaction, which is one of the parts of the concept of life satisfaction, is the realization of needs, demands, and wishes. Life satisfaction mostly includes the entire life of the individual and all the scopes of that life. Life satisfaction is not the satisfaction of a certain situation, but mostly the satisfaction of their entire lives. Life satisfaction means a person's state of being pleasant from different sides, such as happiness, morale (Vara, 1999).

For the first time, Neugarten (1961) the most important issue of people over the years is the satisfaction of life that we know as happiness. Life satisfaction is a state or result that is owned by an individual's desire, comparing what they have. Life satisfaction refers to the result that occurs when a person's desires are compared to what they actually are. Life satisfaction mostly covers the whole life of the individual and more types of that life. Life satisfaction refers not only to satisfaction related to a topic but mostly to satisfaction in their entire lives (Ozer \& Karabulut, 2003).

Decision-making can be defined as a guide to problems that can be experienced when there are many methods that can be reached for an object that is hoped to meet a requirement. It is much more important to think about the aftermath and focus on the outcome when deciding on serious issues. Considering it as a form of behavior, making a decision is in the sense of reaching information or determining the most appropriate goal (Güçray, 2003). 
Decision making is a method of making what best suits the goal of many choices (Budak, 2003).

During decision-making, it was understood that people prefer different methods. Decision-making methods determine how a person will act when they need to make a decision (Ersever, 1996). It is stated that these methods can be applied integrated with them. The methods applied during decision-making can be determined in advance, as well as planned at the time when they are encountered during decision-making. Decision-making methods can create changes in terms of the efforts and effects shown in their practice (Payne et al., 1993). there are four main dimensions applied during decision-making (Raven, 1992). These are: dependent decision-making (influenced by the environment), logical decision-making (choosing the right one), internal reactive decision-making (making decisions with instant emotions), indecision (inability to make decisions).Social events, one's own value judgments, and identity structure in society are the most effective issues in the decision-making phase of the individual (Batçioglu, 1994).

\section{Materials and Methods:}

The research group consists of 150 boys ( 22.58 years) and 63 girls (23 years), a total of 213 (22.79 years) students studying at the Faculty of Sports Sciences of Kocaeli University. Students were randomly selected from the Faculty of Sports Sciences. A survey method was used in this study. The "Personal Information Form" created by the researcher as a data collection tool in the research is the "decision strategies scale" developed by Kuzgun (1993). It consists of 4 subdimensions (logical, internal, dependent decision, unstable decision Strategy). Dagli \& Baysal (2016) used the "life satisfaction scale", which was adapted to Turkish and made valid and secure. In the analysis part of the study, the Spss-20 package program was used. Before analyzing the data, it was decided to perform non-parametric tests by applying a normality test to the data. In the analysis part of the data, descriptive statistics frequency(n) and percentage $(\%)$ values were calculated. Besides, the Bonforoni method was used by applying Mann Whitney-U and Kruskal Wallis $\mathrm{H}$ tests to find the difference between the independent variables in the study. Finally, a Spearman correlation test was performed on dependent variables. The meaning level of the study was accepted as $\mathrm{p}<0.05$.

\section{Results:}

As can be seen from Table-1, the gender variable of the subjects participating in the study having no significant difference in the average order of life satisfaction, decision strategies from their lower dimensions in their logical and internal dimensions. From the lower dimensions of decision-making strategies, significant differences were found in the size of dependent decision-making and indecisive decision-making in terms of average order by gender. It was observed that female students were lower in Dependent decision-making than men, and higher in indecision than men.

Table-1: Mann Whitney-U results by gender variable

\begin{tabular}{|c|c|c|c|}
\hline Gender & $\mathrm{N}$ & Mean Rank & Sum of Ranks \\
\hline \multicolumn{4}{|c|}{ LivesSatisfaction $(\mathrm{U}=-0.38 ; \mathrm{P}=0.7)$} \\
\hline Male & 150 & 105.95 & $15.892,50$ \\
\hline Female & 63 & $109 \cdot 5$ & $6.898,50$ \\
\hline \multicolumn{4}{|c|}{ LogicalDecision $(\mathrm{U}=-0.65 ; \mathrm{P}=0.51)$} \\
\hline Male & 150 & 108.78 & $16.317,00$ \\
\hline Woman & 63 & 102.76 & $6.474,00$ \\
\hline \multicolumn{4}{|c|}{ Intrinsic Decision $(\mathrm{U}=-0.47 ; \mathrm{P}=0.64)$} \\
\hline Man & 150 & $105 \cdot 71$ & $15.856,50$ \\
\hline Woman & 63 & 110.07 & 6.934 .50 \\
\hline \multicolumn{4}{|c|}{ Dependent Decision $(\mathrm{U}=-2.78 ; \mathrm{P}=0.01)$} \\
\hline Man & 150 & 114.53 & $17 \cdot 179 \cdot 50$ \\
\hline Woman & 63 & 89.07 & $5.611,50$ \\
\hline \multicolumn{4}{|c|}{ Indecision $(\mathrm{U}=-1.89 ; \mathrm{P}=0.04)$} \\
\hline Man & 150 & 101.88 & $15.282,00$ \\
\hline Woman & 63 & 119.19 & $7 \cdot 509,00$ \\
\hline Total & 213 & & $\left({ }^{*} \mathrm{P}<.05\right)$ \\
\hline
\end{tabular}

As per Table-2, no signif icant difference in the average order of life satisfaction, decision strategies from the lower dimensions of logical and dependent decision, indecision dimensions was found when looking at the classes of the subjects participating in the study at the university. 3 if the participants ' decision-making strategies are internal to their lower dimension with Class 4. Class, 4 . With class 5.ve it was found that there were signif icant differences between the classes above it.

Table-2: Kruskal Wallis h test results according to participants university classes

\begin{tabular}{|c|c|c|c|c|c|}
\hline Variable & $\mathrm{N}$ & Mean Rank & Variable & $\mathrm{N}$ & Mean Rank \\
\hline \multicolumn{6}{|c|}{ Lives Satisfaction $\left(\mathrm{sd}=3 ; \mathrm{x}^{2}=6.693 ; \mathrm{p}=.082\right)$} \\
\hline 2.Class & 50 & 115.22 & 3.Class & 91 & 103.57 \\
\hline 4.Class & 30 & 85.55 & 5 ve above & 42 & 119.96 \\
\hline \multicolumn{6}{|c|}{ Logical Decision $\quad\left(\mathrm{sd}=3 ; \mathrm{x}^{2}=5.751 ; \mathrm{p}=.124\right)$} \\
\hline 2.Class & 50 & 110.27 & 3.Class & 91 & 104.81 \\
\hline 4.Class & 30 & 87.50 & 5 ve above & 42 & 121.79 \\
\hline \multicolumn{6}{|c|}{ Intrinsic Decision $\left(\mathrm{sd}=3 ; \mathrm{x}^{2}=15.590 ; \mathrm{p}=.001^{*}\right)$} \\
\hline 2.Class & 50 & 93.65 & 3.Class & 91 & 121.31 \\
\hline 4.Class & 30 & 75.95 & 5 ve above & 42 & 114.07 \\
\hline \multicolumn{6}{|c|}{ (Meaning Difference $=3^{* *}-44^{* *}-5$ ) } \\
\hline \multicolumn{3}{|c|}{ Dependent Decision } & \multicolumn{3}{|c|}{$\left(\mathrm{sd}=3 ; \mathrm{x}^{2}=1.440 ; \mathrm{p}=.696\right)$} \\
\hline 2.Class & 50 & 98.21 & 3.Class & 91 & 109.75 \\
\hline 4.Class & 30 & 112.10 & 5 ve above & 42 & 107.86 \\
\hline \multicolumn{6}{|c|}{ Indecision $\left(\mathrm{sd}=3 ; \mathrm{x}^{2}=6.629 ; \mathrm{p}=.085\right)$} \\
\hline 2.Class & 50 & 101.63 & 3.Class & 91 & 114.37 \\
\hline 4.Class & 30 & 83.70 & 5 ve above & 42 & 114.07 \\
\hline Total & 213 & & & & \\
\hline
\end{tabular}

As per the Table-3, significant differences in life satisfaction were found in whether the subjects participating in the study received family support. In addition, no significant differences were found in the family support variable and none of the sub-dimensions of 
decision-making strategies.

Table-3: Kruskal wallis $\mathrm{h}$ test results according to the participants ' status of receiving financial support from the family while studying at University

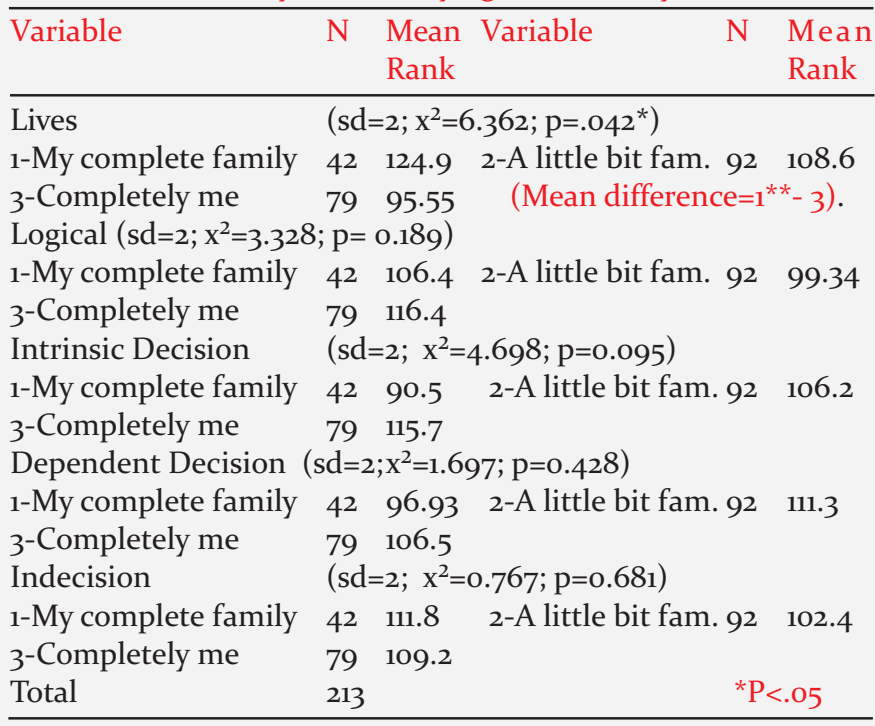

As per Table-4, the subjects involved in the study had a positive direct relationship with their life satisfaction levels and decision-making strategies from their lower dimensions to their dependent decision and logical decision-making Dimensions.

Table 4: Spearman's rho correlation test results between participants college life satisfaction levels and decision-making strategies

\begin{tabular}{llllll}
\hline Variable & & logical & Intrinsic & Dependent & Indecision \\
\hline Lives & $\mathrm{r}$ & $.322^{* *}$ & 0.01 & $.231^{* *}$ & 0.08 \\
satisfaction & $\mathrm{P}$ & 0.00 & 0.90 & 0.00 & 0.24 \\
${ }^{*} \mathrm{P}<.05{ }^{* *} \mathrm{P}<.01$ & & & & \\
\hline
\end{tabular}

As per Table-5, there was no correlation between the ages of the subjects involved in the study and their life satisfaction and decision-making strategies in any direction.

Table 5: Spearman's rho correlation test results between participants college age and life satisfaction levels and decision-making strategies

\begin{tabular}{clllll}
\hline Variable & Satisfaction & logical & Intrinsic & Dependent & Indecision \\
\hline Age $\mathrm{r}$ & -0.087 & -0.079 & 0.13 & 0.052 & 0.013 \\
$\mathrm{p}$ & 0.207 & 0.253 & 58 & 0.449 & 0.854 \\
${ }^{*} \mathrm{P}<.05$ & ${ }^{* *} \mathrm{p}<.01$ & & & & \\
\hline
\end{tabular}

\section{Discussion:}

Based on the results of the study, no significant differences were found between the gender and age variable of the subjects and their life satisfaction levels. It is believed that the reason for this is that gender and age will vary depending on the difficulties that will be experienced, depending on the conditions of life in different periods. Another study that parallels our research result is, Diener \& Myers (1997) determined that there is no linear relationship between age and happiness, stating that a person has problems and internal strife related to himself during each age period.

Huebner (2002) determined that college students have high life satisfaction. He also found that there were no differences in racial, male, and female, class. Diener \& Myers (1997) stated that men had lower depressive and anxiety states but were more prone to bad habits during troubled periods than women. Because of this, it is impossible to say anything clear about inter sex happiness.

Another result from the study was that a significant difference was found between the family support variable and the life satisfaction of students. Students who received family support had higher life satisfaction than those who did not. It is believed that the reason for this is that financial opportunities support students to overcome the difficulties in their lives, basic needs are met, and the university can continue its student life without being dependent on the outside. A similar study was as follows.

It can be said that the region in which students live, the state of the house in which they live, their life-related expectations, and material conditions are reflected in their life satisfaction (Ișik \& Koçak, 2014).

Life satisfaction of people with low financial means is affected compared to people with income growth. Providing as much as one needs is enough for life satisfaction (Diener, 1984).

A significant difference in the logical and internal dimensions of decision strategies has not been found from their lower dimensions. In other sub-dimensions, significant differences were found in dependent decisionmaking and indecisive decision-making, depending on gender. It was observed that female students were lower in Dependent decision-making than men, and higher in indecision than men. In addition, female students were found to be higher than male students, although there was no statistically significant difference in the internal sense. Similar studies are as follows.

In studies related to decision Strategies conducted with university students, female students were found to have higher internal decision-making and indecision dimensions than male students (Keskin et al., 2016; Tiryaki, 1997).

Looking at the class variability of participants, a significant difference in internal dimensions was found from the sub-dimensions of decision-making strategies. 4 . Students in Grades 3 and 5 compared to students in Grades 4. In-class students' internal decision-making was higher. 4 of the reason for this. It is believed that this is due to the fact that the students of the class will take the school graduation and kpss exam. Similarstudies are as follows.

In a study by Bilgiç \& Bilgin (2016), the psychological status of adolescents may vary depending on the kadame they are studying and whether they are male and female. In Deniz (2002) study, the size of indecision varies according to university first and fourth-year students. Orhan \& 
Ültanir (2014), study said that the level of class related to the inner tepisel sub-dimension is important.

It has been found that there is a positive direct relationship between the life satisfaction States of university students and the dimensions of decision-making strategies with dependent decision-making and logical decision-making Dimensions. We have concluded that the reason for this is that people with high life satisfaction receive complete family support in a financial sense. Based on this result, we can say that the material conditions offered by the family to their children move in the same direction as life satisfaction and, in addition, logical decision-making and dependent decision-making. Some similar studies are as follows.

Kaçar (2008), an individual who uses a dependent decision strategy pays attention to the suggestions of others when making decisions, believing that others will know the truth. In this research, The Dependent decision strategies of Public School students private school students go higher than the private school students gave importance to the suggestions of others when deciding, others would come to know the truth believed. Studying in a private school or public school is a matter largely related to the socioeconomic level. The socioeconomic level of students attending private school is higher than those attending public school.

Kohn (1977), found that people at a high socioeconomic level believe that their decisions will be more effective than those at a low socioeconomic level. People at low socioeconomic levels are more likely to believe that they are controlled by external forces, so their decisions are less decisive. Individuals at a high socioeconomic level, on the other hand, can access more resources that improve their decision-making competence. These resources were defined as the opportunity to observe the success of decisions made by the parent, the opportunity to receive help in decision-making, more financial opportunities to increase options, and more experience with decisionmaking (Brown \& Mann, 1990).

\section{Suggestions:}

* In order to improve the quality of life of students, it is necessary to increase the opportunities that university administrations will offer to students.

* Universities, provincial organizations, and many institutions and organizations should be supported in providing conditions related to university youth, especially in which they can conduct their lives with better quality. Free travel, electricity, and electronic equipment assistance, such as increasing dormitory capacities.

* It should be ensured that organizations such as spring festivals, where students themselves feel valued, are increased.

* Scooters and bicycles must be distributed to students on campus.

* Increasing the number and amount of scholarships to be awarded to students should be ensured.

\section{References:}

Batçioglu Genç, G. (1994): Analysis of decision making process (Master's thesis, Inönü University).

Bilgiç, R. \& Bilgin, M. (2016): Examination of the relationship between cognitive flexibility levels and decision strategies according to adolescents ' gender and learning level levels. UsakUni.J. Edu. Res., 2(2):39-55.

Brown, J.E. \& Mann, L. (1990): The Relationship Between Family Structure and Process Variables and Adolescent Decision Making. L.Adolescence, 13(1):25-37.

Budak, S. (2003): Dictionary of psychology. Pub. by: Science and Art Publications.Ankara, Turkey.

DAGLI, A. \& Baysal, N. (2016): Adaptation of life satisfaction scale to Turkish: Validity and Reliability study. Elect. J. Soc. Sci., 15(59).

Deniz, M.E. (2002): Analysis of decision-making strategies and social skill levels of university students in comparison with dominant self-State and some selfquality qualities. Unpublished doctoral dissertation, Selcuk University, Konya, Turkey.

Diener, E. (1984): Subjective Well-Being. Psychol. Bull., 95(3):542575 .

Huebner, E.S., Drane. J.W. \& Valois, R.F. (2000): Levels and demographic correlates of adolescent life satisfaction reports. Sch. Psychol. Int., 21:281-292.

Ersever, Ö.H. (1996): The Effects of an encounter group experience and a short term educational program on the decision making styles of the university students. Unpublished Doctoral Dissertation, Ankara University. Anakar, Turkey.

Güçray, S.S. (2003): The analysis of decision making behaviors and perceived problem solving skills in adolescents. Turk. Online I. Edu. Tech., 2(2):29-37.

Isik, Ö.G. \& Koçak, Ö.F. (2014): An investigation on life satisfaction of students in faculty of communication by different variables. Selçuk Iletisim, 8(3):281-300.

KAÇAR, B. (2008): Decision strategies and Transactional Analysis of High School students examining Ego (I) States in terms of some variables. Yüksek Lisans Tezi, Marmara Üniversitesi, Egitim Bilimleri Enstitüsü. Istanbul, Turkey.

Kohn, M. (1977): Social competence, symptoms and underachievement in childhood: a longitudinal perspective. Pub. by: Wiley, New York.

Kuzgun, Y. (1992): Decision strategy scale: development and standardization. VII. Scientific studies of the National Congress of Psychology.

Kuzgun, Y. (1993): Guidance and psychological counseling in the Turkish education system. I. Edu., 6:3-8.

Myers, D.G. \& Diener, E. (1997): The pursuit of happiness. Sci. Am., 7:40-43.

Orhan, A.A. \& Ültanir, E. (2014): Decision strategies with the professional maturity level of high school students. J. Inst. Soc. Sci. Ufuk Univers., 5:43-55.

ÖZER, M. \& Karabulut, Ö.Ö. (2003): Life satisfaction in the elderly. Turk. J. Geriat., 6(2):72-74. 


\section{ORIGINAL ARTICLE}

Payne, J.W., Bettman, J.R. \& Eric, J. (1993): The adaptive decision maker.

Tiryaki, M.G. (1997): Examination of decision-making behaviors of university students in terms of some variables. LisansTezi High. Hacettepe University Institute Of Social Sciences, Ankara, Turkey.

Yüceloglu Keski·n, D., Bayram, L., Günay Derebasi, D., Bostanci, Ö. \& Kabadayi, M. (2016): Analysis of Decision-Making strategies used by college students according to some demographic variables . Gaziantep Uni.J. Sports Sci., 1(2):1-12.
Ambient Science, 2020: Vol. 07(Sp1); 208-212 DOI:10.21276/ambi.2020.07.sp1.oa29

Vara, S. (1999): Examination of the relationship between job satisfaction and general life satisfaction in intensive care nurses. Unpublished Master's Thesis, Izmir Ege University Institute Of Health Sciences, Izmir, Turkey. 